\title{
Полупроводниковые фотокатоды с эффективным отрицательным электронным сродством для научных и специальных применений
}

\author{
В.В. Бакин ${ }^{1}$, Ю.Б. Болховитянов ${ }^{1}$, С.Н. Косолобов ${ }^{1}$, С.А. Рожков ${ }^{1,2}$, Г.Э. Шайблер ${ }^{1,2}$, А.С. Терехов ${ }^{1}$ \\ ${ }^{1}$ ИФП СО РАН, Новосибирск, 630090, Лаврентьева, 13 \\ ${ }^{2}$ Новосибирский государственный университет, Новосибирск, 630090, Пирогова, 2 \\ тел:+7 (383) 330-85-08, факс:+7 (383) 333-27-71, эл. почта: terek@isp.nsc.ru
}

DOI 10.34077/RCSP2021-25

Обсуждаются результаты экспериментальных исследований и разработок полупрозрачных р $\mathrm{GaAs}(\mathrm{Cs}, \mathrm{O})$ - фотокатодов с эффективным отрицательным электронным сродством (ОЭС) [1], выполненных в ИФП СО РАН. Кроме применений в наиболее современных приборах ночного видения, полупрозрачные $\mathrm{p}$ - $\mathrm{GaAs}(\mathrm{Cs}, \mathrm{O})$ - фотокатоды используются также и в многоканальных быстродействующих детекторах одиночных фотонов для фундаментальных научных исследований [2]. Важной областью применений ОЭС - фотокатодов являются и фотоэлектронные инжекторы, генерирующие интенсивные пучки «моноэнергетических» [3] и спин-поляризованных [4] фотоэлектронов. Основными характеристиками ОЭС - фотокатодов, важными для большинства их применений, являются: квантовая эффективность $(\mathbf{Q E})$; вероятность выхода фотоэлектронов в вакуум $\left(\mathbf{P}_{\mathbf{e}}\right)$, стабильность $\mathbf{P}_{\mathbf{e}}$ от времени $(\mathbf{t})$ и энергетические распределения эмитированных фотоэлектронов по их «продольным» $\left(\boldsymbol{\varepsilon}_{\mathbf{l o n}}\right)$ и «поперечным» $\left(\boldsymbol{\varepsilon}_{\mathrm{tr}}\right)$ энергиям, соответственно. В докладе обсуждаются (1) «самоорганизация» атомной структуры $(\mathrm{Cs})$ - и $(\mathrm{Cs}, \mathrm{O})$ - покрытий; (2) энергетическая диаграмма ОЭС - интерфейсов; (3) доминирующие механизмы упругого и неупругого рассеяния фотоэлектронов на ОЭС - интерфейсах при их переходе из объёма полупроводника в вакуум. «Самоорганизация» атомной структуры $(\mathrm{Cs})$ - и $(\mathrm{Cs}, \mathrm{O})$ - покрытий изучалась в экстремально высоком вакууме с использованием экспериментальных методик, не влияющих на их атомную структуру. Для изучения энергетических диаграмм ОЭС - интерфейсов и доминирующих механизмов упругого и неупругого рассеяния фотоэлектронов при их переходе из объёма полупроводника в вакуум мы использовали самодельные миниатюрные спектрометры, «позволяющие» проводить эксперименты в интервале температур $4 \mathrm{~K} \div 350 \mathrm{~K}$. Основные выводы нашей работы состоят в следующем. (1) ОЭС - интерфейс с оптимальным (Cs,O) - покрытием является замкнутой термодинамической системой, удельная свободная энергия которой обеспечивает его стабильность при температурах $\leq 350 \mathrm{~K}$. (2) Формирование оптимального $(\mathrm{Cs}, \mathrm{O})$ - покрытия сопровождается частичным упорядочением атомной структуры ОЭС - интерфейса, благодаря которому снижаются его удельная энтропия и, как следствие, вероятность диффузного рассеяния фотоэлектронов при их переходе из полупроводника в вакуум [5].

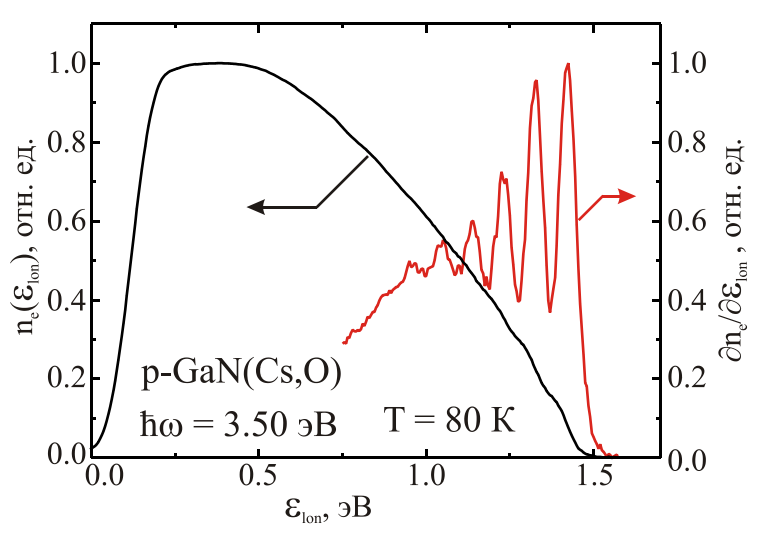

(3) Энергетическая диаграмма оптимального $(\mathrm{Cs}, \mathrm{O})-$ покрытия указывает на его «металлическую природу». (4) Испускание фотоэлектронами продольных оптических фононов является доминирующим механизмом их неупругого рассеяния на ОЭС интерфейсах [6,7]. Неопубликованные результаты наших недавних экспериментов показали также, что рассеяние фотоэлектронов из $\mathbf{\Gamma}$ - долины в боковые $\mathbf{L}-$ долины в приповерхностной области пространственного заряда ОЭС - интерфейса с участием коротковолновых оптических фононов сопровождается рассеянием не только их энергии, но и импульса.

Работа выполнена при поддержке РФФИ (проекты 12-02-00418; 16-02-00534; 19-02-00517).

\section{Лuтература}

[1] Ю.Б. Болховитянов и др. // Письма в ЖТФ. 1990. Т.6. №7. С.25-29.

[2] В.Л. Плохотниченко и др. // Астрофизический бюллетень. 2020. Т.75, вып.1, С. 66-77.

[3] O. Novotný et. al // Science. 2019. V. 365, Iss. 6454, P.676-679.

[4] P. Drescher et. al // Nuclear Instrum. and Methods A. 1996. V.381, P.169-173.

[5] В.В. Бакин и др. // Письма в ЖЭТФ. 2018. Т.108. вып.3, С.180-184.

[6] Д.А. Орлов и др. // Письма в ЖЭТФ. 2000. Т.71, вып.4. С. 220-224.

[7] В.В. Бакин и др. // Письма в ЖЭТФ. 2016. Т.104. вып.2, С.128-132. 